\title{
NOS MEANDROS DAS RESTRIÇÕES INTERNACIONAIS: O BRASIL E AS POSSIBILIDADES PARA FORMULAÇÃO DE POLÍTICAS INDUSTRIAIS
}

\author{
Jonatas Luis Pabis
}

\section{RESUMO}

A realização de políticas industriais como política pública não é algo novo na teoria econômica. Há, inclusive, uma vasta literatura sobre o tema, suas justificativas, objetivo e modos de promoção. Contudo, o avanço do processo de integração em blocos regionais e da regulamentação multilateral do comércio internacional implica na busca por políticas mais homogêneas em vários aspectos e reduzem a possibilidade de políticas industriais independentes. Neste novo cenário, pouco tem se discutido sobre o impacto dos acordos internacionais sobre as possibilidades e restrições a formulação de políticas industriais. Partindo da noção de Amartya Sen que desenvolvimento consiste em ganhos sociais e de liberdades substancias, este artigo discute a relação de uma política industrial brasileira voltada ao desenvolvimento nacional e suas possibilidades de implementação diante dos compromissos e diretrizes da Organização Mundial do Comércio.

\section{ABSTRACT}

Industrial policies as public policies are not a new topic in economic theory. There is a huge literature about the issue, its justification, aims and methods of enforcement. Nevertheless, ongoing process of economic integration and multilateral regulations under World Trade Organization leads to the search for more homogeneous policies in various aspects and decrease possibilities of independent industrial policies. In this new scenario, there has been little discussion about impacts of international agreements on possibilities and restrictions to formulation of industrial policies. From Amartya Sen's perspective of development, which consists in social gains and substantial 
liberties, this article discuss the relation between Brazilian industrial policy to national development and its enforcement possibilities against commitments and guidelines from World Trade Organization.

INDICADORES: Política Industrial, Comércio Internacional, Acordos da OMC

\section{INTRODUÇÃO}

Até os anos 1960 a comercialização de produtos primários representava cerca de três quintos das trocas mundiais. Hoje além de representarem apenas um quinto das trocas totais, constatou-se que seus ganhos beneficiam pequena parcela da população. A renda deles proveniente não se espalha ao longo da cadeia produtiva gerando ganhos para toda a sociedade como ocorrem na indústria manufatureira. Além disso, as disputas neste campo restringem-se a tarifas, cotas ou restrições tradicionais, enquanto os mercados de produtos industrializados permitem maiores possibilidades de negociação.

As nações que aumentaram sua participação no comércio internacional durante as duas últimas décadas foram aquelas que apostaram nos setores de manufatura. Um dos grandes erros dos Estados periféricos foi ter confundido abertura com estratégia. Imaginou-se erroneamente que 0 fluxo de investimentos garantiria um grande volume de exportações.

Como a abertura foi inevitável e o equilíbrio na balança nem sempre possível, a definição de uma estratégia nacional torna-se cada vez mais imperiosa, principalmente, porque as pressões internacionais lideradas por outros atores e organizações têm dificultado crescentemente os espaços para desenvolvimento de políticas internas.

Dentro desse contexto, o Brasil deve responder ao desafio da inserção competitiva no comércio internacional, ao mesmo tempo, em que promove um processo de inclusão social de sua população. Exportar mais, porém, não significa produção adicional, mas sobretudo desenvolvimento de capacidades inovativas e tecnológicas.

Revista Brasileira de Direito Internacional, Curitiba, v.7, n.7, jan./jun.2008 
A capacidade de inovação é cada vez mais o elemento que separa as economias avançadas das subdesenvolvidas. Assim, é fundamental a realização de políticas públicas voltadas ao aumento da competitividade, da eficiência econômica e participação no comércio internacional em mercados de alto valor agregado.

Uma das principais estratégias voltada ao incentivo do desenvolvimento da indústria nacional e crescimento das exportações manufatureiras ou tecnológicas é chamada política industrial. Até recentemente, países como o Brasil utilizavam a substituição de importações como a principal metodologia.

Com o esvaziamento deste método na era da liberalização comercial, os países sobretudo em desenvolvimento buscam novas estratégias para superar este gap tecnológico. Todavia, a regulamentação internacional do comércio limita o espaço de autonomia nacional para definição destas políticas. O presente artigo visa estudar as restrições impostas pelos Acordo de Subsídios e Medidas Compensatórias (ASMC) e Acordo sobre Medidas de Investimento Relacionadas ao Comércio (TRIMS) da Organização Mundial do Comércio (OMC).

\section{A INSERÇÃO BRASILEIRA NO COMÉRCIO INTERNACIONAL}

Apesar da constante busca da superação das vulnerabilidades externas, a pauta brasileira ainda é concentrada em produtos primários e a intensidade tecnológica as exportações brasileiras é muito menor que a média mundial. $40 \%$ das exportações são de commodities, enquanto a média internacional é de $13 \%{ }^{1}$. Para completar este quadro de atraso, parte considerável do comércio de bens de maior intensidade tecnológica é, intraindustrial, ou seja, complementar à tecnologia da empresas-matrizes no exterior.

1 TONI, Jackson de. A Inovação Tecnológica, políticas públicas e o Futuro da Indústria no Brasil in Opinio, n. 17. 2006.

Revista Brasileira de Direito Internacional, Curitiba, v.7, n.7, jan./jun.2008 
Essa falta de produtos de alto valor agregado tem levado a uma redução na participação brasileira no comércio internacional com relação ao total de trocas mundiais. Enquanto as exportações brasileiras aumentaram $4,6 \%$, o comércio internacional cresceu em cerca de $7 \%$ anualmente ao longo dos últimos 20 anos. Isso levou à queda da participação país no total nas trocas mundiais de $1,39 \%$ para $0,79 \%^{2}$. Além disso, apesar de relativamente pequeno em relação ao todo, o Brasil comercia com uma importante diversidade de países. Contudo, em um universo de 4 milhões de exportadores, apenas um mil destas empresas respondem por $88 \%$ das exportações.

Do outro lado deste quadro desanimador, os últimos anos revelaram um país com forte atuação multilateral no contexto sul-americano e mundial, trabalhando como um coordenador de interesses do bloco dos países em desenvolvimento sem interesses hegemônicos. Internamente é um dos poucos países em desenvolvimento que possui firmes possibilidades de obter ganhos de escala e viabilizar o crescimento da inserção internacional de bens manufaturados de maior intensidade tecnológica, o que the confere um grande potencial para a abertura de novos mercados. Além disso, conta com recursos naturais e humanos, infra-estrutura básica, capacidade industrial instalada e competência empresarial que precisam apenas ser mais bem mobilizadas.

Diante dessa variedade, é seguramente um país muito mais complexo que outros países que atingiram o sucesso como Chile e Cingapura, o que dificulta a articulação de políticas, exigindo uma sólida visão dos objetivos comuns das partes envolvidas nos esforços de desenvolvimento.

Assim, a identificação dos objetivos nacionais lança luz sobre as ações que sejam estratégias para assegurar um crescimento estável e uma atuação mais eficiente do setor público. A gama de ações é variada, envolvendo desde a desoneração tributária até a criação de centros logísticos no exterior passando pela consolidação de marca associada ao país nos mercados compradores. Não se pode deixar também de mobilizar grandes empresas

2 BRASIL. MINISTÉRIO DO DESENVOLVIMENTO, INDÍSTRIA E COMÉRCIO. (2004) Diretrizes de Política Industrial, Tecnológica e de Comércio Exterior. Brasília: 2004.

Revista Brasileira de Direito Internacional, Curitiba, v.7, n.7, jan./jun.2008 
líderes nacionais, clusters de pequenas e médias empresas e subsidiárias de multinacionais no país.

No presente artigo vai se focar na formulação de políticas industriais de incentivo tecnológico como instrumento para que o país atinja um crescimento sustentável e a ampliação da competitividade internacional das empresas brasileiras e das exportações de produtos de alta tecnologia com contínuo investimento em infra-estrutura, inovação e capacitação humana.

\section{A POLÍTICA INDUSTRIAL}

Todos os Estados procuram proteger ou adquirir vantagens comparativas na produção de certos bens seja por questões estratégicas ou conjunturais. Em cada momento, certos países têm maior capacidade de produção de certos bens e serviços, são aqueles que estão na vanguarda do desenvolvimento científico e tecnológico. É essa situação que permite a certas populações se beneficiarem de um padrão de renda mais elevado, e não meramente de uma maior produtividade.

A partir desta situação espalhou-se o mito de que a geração de inovações tecnológica seria um processo aleatório e exclusivo de países que possuíam as vantagens comparativas. Como conseqüência, ocorreria de modo natural e não conflituoso a difusão destas inovações na economia internacional. Pouco se discute, porém, que países como Estados Unidos e Japão atingiram suas posições de exportadores de tecnologia com grande esforço político.

De modo geral, a intervenção do Estado na economia se deu a partir da crise de 1929 e a revolução keynesiana dos anos 20. Até então, acreditavase que o mercado alocaria os recursos eficientemente, por isso questionava-se a existência de uma política voltada ao incentivo industrial.

No Brasil raramente se deu a devida atenção a formulação de uma política científica e tecnológica em programas coordenados com outros programas relativos a universidades, indústria e comércio exterior. Até meados na década de 90, acreditava-se que a melhor política industrial era não ter 
política. Com a percepção da importância de produtos de alto valor agregado na pauta de exportação a partir do desenvolvimento de inovações nacionais e a incapacidade dos agentes privados de países periféricos ganharem espaço no mercado internacional, o tema voltou retomou seu lugar nos debates.

Não se discutirá aqui a natureza jurídica de instrumentos da política industrial. $O$ importante a ressaltar é que a ela não é uma mera busca de objetivos econômicos. Sua natureza é sim política. A partir da competência constitucionalmente definida no artigo 174, o administrador adota mecanismos adequados para atingir este fim. Seja por meio de lei ou ato administrativo, a política industrial deve se compatibilizar com os princípios da ordem econômica, sendo que tais políticas nada mais são do que instrumentos, ou nas palavras de Washington Peluso, “objetivo-meio' para se atingir o 'objetivofim' expresso na ideologia, ou seja, na Constituição" ${ }^{3}$.

Antes de apresentar um conceito, deve-se atentar para o conceito de regulação econômica ou planejamento econômico, dentro a política industrial insere-se. Nas palavras de Grau, planejamento econômico é

"a forma de ação estatal, caracterizada pela previsão de comportamentos econômicos e sociais futuros, pela formulação explícita de objetivos e pela definição de meios de ação coordenadamente dispostos, mediante a qual se procura ordenar, sob o ângulo macroeconômico, o processo econômico, para melhor funcionamento da ordem social, em condições de mercado".4

Neste sentido, estas políticas são concebidas em um contexto macroeconômicos no qual também se trabalha com fatores como inflação, taxa de câmbio e juros, ao mesmo tempo em que elege e intervenção em certos setores e atividades econômicas específicas.

Há na literatura vários conceitos e concepções de política industrial. Adota-se aqui o conceito utilizado por Milton de Abreu Campanario e Marcello Muniz da Silva,

\footnotetext{
${ }^{3}$ SOUZA, Washington Peluso Albino de. Primeiras Linhas de Direito Econômico. 5.ed. São Paulo: LTr, 2003. p. 248

${ }^{4}$ GRAU, Eros. Planejamento Econômico e Regra Jurídica. São Paulo: RT, 1977. p. 65
}

Revista Brasileira de Direito Internacional, Curitiba, v.7, n.7, jan./jun.2008 
"política industrial é a criação, a implementação, a coordenação e o controle estratégico de instrumentos destinados a ampliar a capacidade produtiva e comercial da indústria, a fim de garantir condições concorrenciais sustentáveis nos mercados interno e externo"5.

A política industrial busca corrigir as falhas de mercado aumentando a competitividade empresarial e sistêmica e impulsionando o uso mais eficaz dos recursos naturais. Ao fomentar inovações tecnológicas e o aprimoramento das capacidades locais, tais intervenções facilitam a difusão de benefícios direitos tanto ao setor industrial como os demais setores da economia, é o chamado "efeito multiplicador". Se por um lado é uma resposta às falhas temporais do mercado, por outro exige uma visão de objetivos comuns de modo a formular uma política coerente e articulada com a estratégia de desenvolvimento do país.

Este foi o objetivo que o governo buscou definir nas "Diretrizes de Política Industrial, Tecnológica e de Comércio Exterior" ${ }^{6}$. O governo pretende assim elevar a participação do comércio exterior no PIB do país dos atuais $20 \%$ para $35 \%$. Em síntese, deseja-se promover a competitividade da indústria; ampliar acesso a mercados e a competitividade setorial dos segmentos industriais tradicionais; Fomentar o desenvolvimento dos complexos industriais de produtos com maior valor agregado e alto conteúdo tecnológico; incentivar as atividades de pesquisa e desenvolvimento, a criação e o desenvolvimento de novas tecnologias e aumentar as exportações e incentivar a substituição competitiva de importações, de forma a reduzir a excessiva exposição externa da economia. ${ }^{7}$

A política industrial não se coloca como alternativa ou se contrapõe à execução de políticas e ao desenvolvimento dos demais setores da economia. Ela é justamente complementar a políticas voltadas a outras áreas.

Certamente a política atual não poderá esquecer o passado de desconfianças que a cerca. Enquanto uma ameaça está na miragem do

\footnotetext{
${ }^{5}$ FLEURY, Afonso. FLEURY, Maria Tereza Leme. Política Industrial 1. São Paulo: Publifolha, 2004. p. 14

${ }_{7}^{6}$ BRASIL. MINISTÉRIO DO DESENVOLVIMENTO, INDÍSTRIA E COMÉRCIO (2004)

7 BRASIL. MINISTÉRIO DO DESENVOLVIMENTO, INDÍSTRIA E COMÉRCIO.(2004)

Diretrizes de Política Industrial, Tecnológica e de Comércio Exterior. Brasília: 2004.
}

Revista Brasileira de Direito Internacional, Curitiba, v.7, n.7, jan./jun.2008 
crescimento, a outra está nos próprios adeptos, sobretudo nos mais fervorosos. Os excessos, a substituição além das medidas, intervenções unilaterais, exageros à revelia da demanda levam a resultados desastrosos. Por isso, a dificuldade de se operar este instrumento sem distorcer o mercado.

Como último direcionamento, uma política industrial consistente deve atentar ao elemento mais fundamental na produção do conhecimento científico e tecnológico: o ser humano. A produtividade individual é que pode levar ao aumento do bem-estar dos trabalhadores, empresários e demais classes sociais. Por isso deve-se enfatizar a implantação de centros de formação de pessoal de alto nível em território nacional.

\section{DESENVOLVIMENTO}

Essa preocupação central com o ser humano vai de encontro à noção de desenvolvimento do economista Amartya Sen. Para o autor, desenvolvimento é um processo de transformação de uma sociedade com ganhos não só econômicos, mas também sociais de modo que reflitam a expansão de liberdades formais e substanciais das pessoas para que possam desenvolver todas as suas potencialidades o que permite, por sua vez, uma maior expansão das liberdades das pessoas, formando, assim, um ciclo vicioso para que todos possam exercer suas liberdades essenciais.

O desenvolvimento é, assim encarado como a eliminação de privações de liberdade que limitam as escolha e as oportunidades das pessoas de exercerem de forma ponderada sua condição de indivíduo ${ }^{8}$. A liberdade consiste nas possíveis combinações de diversas coisas que uma pessoa pode considerar importante e possa realmente buscar sua realização. Nesta noção pobreza não é apenas um baixo nível de renda, mas também a privação de capacidades básicas.

Para Sen, a liberdade faz parte do desenvolvimento e também o promove. As liberdades políticas, oportunidades econômicas e poderes sociais

\footnotetext{
${ }^{8}$ SEN, Amartya. Desenvolvimento como Liberdade. São Paulo: Companhia das Letras, 2002. p. 10
}

Revista Brasileira de Direito Internacional, Curitiba, v.7, n.7, jan./jun.2008 
influenciam as pessoas na realização das atividades, ao mesmo tempo em que as instituições que proporcionam estas oportunidades são influenciadas pelo exercício das liberdades por estas pessoas. Assim, deve-se fazer uma análise integrada das atividades econômicas, sociais e políticas, da multiplicidade de instituições e condições de agente a partir da noção de indivíduo como agente ativo de mudança na sociedade para se entender o desenvolvimento.

Portanto, uma política industrial além de incentivar o desenvolvimento de tecnologias, permite às populações exercer todas suas potencialidades de modo a promover um ganho de liberdades substanciais levando a ganhos sociais e econômicos na promoção do desenvolvimento nacional.

\section{OS COMPROMISSOS INTERNACIONAIS}

Atualmente, a integração econômica mudou completamente o modo e as possibilidades de formulação de políticas industriais nacionais. Não é mais possível mais fazer um estudo destas políticas nacionais sem ligá-las a fenômenos que ocorrem além das fronteiras territoriais.

Passam, então, a ser também objeto de regulamentação tanto de blocos regionais como organismos mundiais. Por isso, a constatação de que as pressões internacionais lideradas por concorrentes e instituições internacionais dificultam crescentemente espaços para exercício de políticas industriais nacionais.

À medida que o processo de integração no Mercosul avança, implica na busca por políticas econômicas mais homogêneas em vários aspectos. Além dos blocos regionais, os próprios organismos multilaterais do comércio internacional reduzem a possibilidade de políticas industriais independentes.

No fórum da Organização Mundial do Comércio (OMC), os paísesmembros têm suas políticas nacionais rigidamente limitadas. No contexto de políticas industriais ao estarem mais diretamente relacionados com a intervenção do Estado na economia em favor do desenvolvimento, dois acordos assumem maior relevância: o Acordo sobre Medidas de Investimento 
Relacionadas ao Comércio (TRIMS) e o Acordo Sobre Subsídios e Medidas Compensatórias (ASMC).

Os acordos preocupam-se mais com o efeito causado no mercado internacional do que com as medidas propriamente tomadas. Pouco importa se subsídios ou alguma forma de proteção é direcionada a empresas nacionais ou subsidiárias internacionais, o importante é o "trade effect". Isto significa que qualquer política que se deseje implementar deve, antes de tudo, estar ancorada em algum dispositivo acordado.

A possibilidade de promoção de políticas industriais voltadas a exportação foi reduzida a instrumentos mais gerais impedindo que os países desenvolvam setores específicos através de instrumentos bem direcionados. Quanto a políticas de incentivo o tratamento em geral dispensando é a limitação de certo período para adequação conforme as regras da organização.

Isso é reflexo da noção que prevaleceu na Rodada de Tóquio no sentido de que os países em desenvolvimento deveriam assumir gradualmente as mesmas obrigações que os membros desenvolvidos da organização. Assim as discussões foram focadas no tempo necessário e possível extensão para que os membros implementar parte dos acordos negociados.

Nos próximos dois subcapítulos faz-se uma análise de alguns dispositivos que restringem a autonomia nacional na formulação de políticas industriais no âmbito da OMC.

\subsection{O ACORDO DE SUBSÍDIOS E MEDIDAS COMPENSATÓRIAS DA ORGANIZAÇÃO MUNDIAL DO COMÉRCIO}

Por afetar diretamente os fluxos do comércio internacional, o tema dos subsídios esteve presente nas discussões desde o início das negociações multilaterais. Mas foi apenas a Rodada Tóquio que se firmou um acordo. $O$ código foi, então, aperfeiçoado durante e Rodado Uruguai dando origem ao Acordo sobre Subsídios e Medidas Compensatórias (ASMC).

Em seu artigo $1^{\circ}$, o ASMC traz a definição geral de subsídios, a qual se caracteriza pela:

Revista Brasileira de Direito Internacional, Curitiba, v.7, n.7, jan./jun.2008 
a) Contribuição financeira do governo ou qualquer órgão público, mesmo entidades privadas desempenhando papel governamental;

b) Existência de vantagem para o beneficiário;

c) Especificidade.

$\mathrm{Na}$ controvérsia Canadá - Medidas Afetando a Exportação de Aeronaves Civis, o Órgão de Apelação da OMC reafirma a existência de dois elementos distintos na constituição do subsídio: uma contribuição financeira governamental e um benefício dela decorrente. Para a análise destes fatores,

"the marketplace provides an appropriate basis for comparison in determining whether a "benefit" has been "conferred", because the trade-distorting potential of a "financial contribution" can be identified by determining whether the recipient has received a "financial contribution" on terms more favorable than those available to the recipient in the market" .

O mercado que aqui se fala é o mesmo no qual se concede $O$ subsídio $^{10}$. Já o Órgão de Apelação $(\mathrm{OA})$ reverteu a conclusão permitindo a autoridade investigadora utilizar parâmetros de preços de outros mercados quando os preços em questões estiverem distorcidos. Para isso devem refletir os requisitos do artigo 14 (d).

A contribuição não necessariamente deve ser financeira. O painel de Softwood Lumber considerou que o direito de corte de árvores permitido pelo Canadá era o mesmo que dar as toras, bens, às madeireiras, caracterizandose, assim, um provimento de bens e conseqüentemente e uma contribuição financeira.

Nesta controvérsia, examinou-se a transferência do benefício ao longo da cadeia produtiva. Inicialmente, o painel entendeu que não se poderia considerar que os subsídios concedidos aos produtores seriam automaticamente transferidos para os usuários, principalmente se as transações ocorrem em condições normais do mercado. É preciso analisar em que medidas os benefícios foram transferidos.

9 Canadá - Measures affecting the export of civilian aircrafts (WT/DS70/AB/R) par. 157

${ }^{10}$ Softwood Lumber (DS/236 e DS/257)

Revista Brasileira de Direito Internacional, Curitiba, v.7, n.7, jan./jun.2008 
Indo além do conceito do artigo $1^{\circ}$, o OA no caso Brasil - PROEX ${ }^{11}$ considerou que a concessão de subsídios ocorre quando o benefício é usufruído. Desta forma, o momento da concessão não é necessariamente o mesmo em que o subsídio é usufruído.

$\mathrm{O}$ artigo $2^{\circ}$ regulamenta a configuração da especificidade que se verifica quando:

a) Os subsídios forem limitados a empresas por estipulação legal ou de fato;

b) Inexistirem critérios claros e objetivos sobre 0 acesso ao subsídio e seu montante de fácil conhecimento por todos os grupos;

c) Houver determinação geográfica dentro do território concedente

Ainda na controvérsia Softwood Lumber, o painel considerou que o art. $2^{\circ}$ se refere a disponibilidade limitada do subsídio a certas empresas, não para um subgrupo dentro de empresas elegíveis.

Considerando os efeitos e finalidades, o ASMC classificou os subsídios em proibidos, acionáveis e não acionáveis. A primeira categoria, regulada pelo artigo $3^{\circ}$, relaciona-se ao desempenho exportador do beneficiário ou uso de produtos nacionais em detrimento de produtos estrangeiros. O simples fato de se conceder subsídios a empresas que exportam não implica na sua proibição $^{12}$. A nota 4 do ASMC apresenta as condições para a determinação do contigencionamento de fato.

Na controvérsia Canadá - Aeronaves Civis ${ }^{13}$, o painel analisou se os subsídios do programa "Technology Partnership Canada" seriam concedidos para a Bombardier caso a empresa não fosse exportadora. Ressaltando que a empresa exporta grande parte da produção, o objetivo do programa era apoiar projetos de P\&D em potencial exportador, concluiu-se que a assistência não teria sido concedida não fosse a perspectiva de exportações, o que se condicionava ao desempenho exportador.

\footnotetext{
11 DS/46

${ }^{12}$ Aeronaves civis canadenses (DS/222)

${ }^{13}$ DS 70
}

Revista Brasileira de Direito Internacional, Curitiba, v.7, n.7, jan./jun.2008 
No entendimento do $\mathrm{OA}$, a nota 4 é clara em afirma a caracterização de três elementos: a imposição de alguma condição na performance exportadora; a vinculação a exportações efetivas ou esperadas; em relação às exportações esperadas ("antecipated"), tal fato também deve ser demonstrado e analisado em separado.

Os subsídios acionáveis são aqueles proibidos na medida em que causem danos a indústria doméstica de outro Estado, gerem sérios prejuízos e anulem benefícios a outros membros da OMC. É o que estabelece o artigo $5^{\circ}$ do ASMC.

No caso do Algodão ${ }^{14}$, envolvendo Brasil e Estados Unidos, o painel entendeu que para caracterização que grave dano bastava a ocorrência de um efeitos mencionados, no caso o efeito sobre os preços. Em outras palavras, verificada a supressão dos preços não seria necessário depois disso, analisar se a situação foi grave ou não. Assim, após esta análise, passou a avaliar os impactos no mercado mundial. No caso Korea - Measures Affecting Trade in Commercial Vessel ${ }^{15}$ o painel considerou que o "mesmo mercado" pode ser o mercado internacional.

Adiante, o painel concluiu que os métodos e conceitos da Parte $V$ do ASCM relativos ao cálculo do montante de subsídios para aplicação de medidas compensatórias não são diretamente aplicáveis no exame das disposições da Parte III do acordo. Fornecem apenas diretrizes para a determinação de grave dano.

Diferente é o caso analisado em Indonesia - Certain Measures Affecting the Automobile Industry em que se avaliava o "grave dano" causado pelos efeitos negativos da restrição de importações de automóveis naquele mercado. Desta forma, na análise se o programa de apoio a indústria automotiva da Indonésia tinha gerado "grave dano" aos interesses da Comunidade Européia e dos Estados Unidos, considerou-se o mercado indonésio, ou seja, do país que concede os subsídios.

\footnotetext{
${ }^{14} \mathrm{DS} / 267$

${ }^{15} \mathrm{DS} / 273$
}

Revista Brasileira de Direito Internacional, Curitiba, v.7, n.7, jan./jun.2008 
O artigo $8^{\circ}$ regulamenta os subsídios que a princípio não podem ser questionados, os ditos não acionáveis. Considerados pouco distorcivos ao comércio, esta categoria é bem restrita até porque o acordo busca evitar que se dê a roupagem de não-acionável a outros subsídios. Caracterizam-se pela:

a) Generalidade, não específicos no sentido do artigo $2^{\circ}$

b) Assistência a regiões desfavorecidas dentro do território nacional;

c) Assistência a atividade de pesquisa realizada por empresas ou instituições acadêmicas;

d) Estudo para adaptação de estruturas existentes a exigências ambientais.

Não se pode deixar de mencionar o tratamento especial e diferenciado dispensado a países em desenvolvimento. Apesar do reconhecimento de que os subsídios podem desempenhar importante papel no projeto de desenvolvimento econômico destes países, o artigo 27 permite apenas os países de menor desenvolvimento relativo a utilização de subsídios vinculados a exportação.

No caso Indonésia - Autos $^{16}$, o painel entendeu que é possível opor uma demanda contra países em desenvolvimento alegando grave prejuízo, estando presentes as situações do artigo 6.1.

\subsection{O ACORDO SOBRE MEDIDAS DE INVESTIMENTO RELACIONADAS AO COMÉRCIO DA ORGANIZAÇÃO MUNDIAL DO COMÉRCIO}

No caso do TRIMS, a regra geral do artigo 5.2 é que todas as medidas de investimento notificadas com base no artigo 5.1 deveriam ser eliminados dentro de dois anos, abrindo-se a exceção para cinco anos para os países em desenvolvimento e de sete para os países menos desenvolvidos.

${ }^{16}$ Indonesia - Autos (WT/DS54/R, WT/DS55/R,WT/DS56/R, WT/DS59/R, WT/DS64/R)

Revista Brasileira de Direito Internacional, Curitiba, v.7, n.7, jan./jun.2008 
Como a utilização do TRIMS nas áreas de ciência e tecnologia é necessária para que sua participação no comércio de produtos de alto valor agregado não sofra um declínio considerável, o Brasil, juntamente com a Índia, chamou a atenção para a necessidade de maior flexibilidade do acordo. Sobretudo, devido a fragilidade dos países periféricos em relação às crises internacionais, o superávit comercial se torna uma meta fundamental. Para que ele ocorra podem-se aumentar as exportações ou reduzir as importações. Uma vez que a primeira hipótese é a única que não deprecia o comércio multilateral, a vinculação do TRIMS ao desempenho exportador destes países pode ser uma ótima saída.

No relatório, os dois países propunha uma emenda ao artigo 4, ampliando a permissão para

\footnotetext{
"a) promover a capacitação das indústrias nacionais de manufatura em setores de alto valor agregado ou de tecnologia intensiva;

b) estimular a transferência ou desenvolvimento de tecnologia (...)

f) aumentar a capacidade de exportação em casos de déficit monetário;

(...)"
}

Além das medidas de investimento, grande parte da política indústria está atrelada a utilização de subsídios. Assim como no TRIMS, o tratamento dispensando pelo Acordo Sobre Subsídios e Mediadas Compensatórias está longe de conferir a flexibilidade de que os países em desenvolvimento necessitam na condução de suas políticas, a sistemática adota é ampliação do prazo de adaptação.

Conforme prevê o artigo 27.2(a), os países relacionados no seu anexo VII não estão sujeitos a obrigação geral do artigo 3.1 (a) de eliminar os subsídios à exportação enquanto os demais países ficam obrigados a aplicar uma redução gradual em um período de 8 anos, que pode ainda ser estendido conforme exame de justificações pelo Comitê de Subsídios e Medidas Compensatórias. Esta exceção do art. 27.2(b) é suspensa para exportação de produtos quando estes já tenham adquirido competitividade no mercado 
internacional, ou seja, exportações que tenham adquirido 3,25\% do comércio internacional para aquele produto durante dois anos consecutivos.

Aqui não se pode esquecer que todo e qualquer subsídio concedido por um país em desenvolvimento, mesmo que dentro das condições do ASMC pode ser contestado por outros membros da OMC. O objetivo do tratado é banir subsídios que causam efeitos diretos sobre o comércio internacional, abrindo, porém algumas exceções na promoção de indústrias, o que também podem ser utilizados por Membros desenvolvidos.

Ainda vale mencionar rapidamente, o rígido disciplinamento na proteção de direitos de propriedade intelectual, direitos autorais, marcas, patentes, design industrial, entre outros pelo Acordo sobre medidas relacionais aos Direitos de Propriedade Intelectual (TRIPS). O que coloca um pesada barreira na incorporação tecnológica às produções locais de países mais pobres.

Conforme concluem Bora, Lloyd e Pangestu, a política industrial dos países em desenvolvimento deveriam ser "examined further within the context of an 'appropriate' transition time or perhaps even a performance-based measure such as the degree of discrimination towards imports or effective rate of assistance"17.

O fato que os países não possuem mais a mesma autonomia de antes e pouco se avançou na ajuda aos países em desenvolvimento além da dilação dos prazos.

\section{CONCLUSÃO}

O esgotamento do modelo de substituição de importações acompanhado pela abertura econômica ocorrida nas últimas décadas provocou profundas transformações em todas as economias emergentes. Mais do que qualquer déficit financeiro, a abdicação de um projeto de desenvolvimento

17 BORA, Bijit; LLOYD, Peter J.; PANGESTU, Mari. Industrial Policy and the WTO. Genebra: WTO Secretariat, 1999. p. 34

Revista Brasileira de Direito Internacional, Curitiba, v.7, n.7, jan./jun.2008 
preocupado com as necessidades nacionais parecer ter sido um dos maiores empecilhos para uma exitosa inserção global dos países em desenvolvidos.

A integração do país a economia mundial não substitui estratégias de desenvolvimento. Para que o acesso ao mercado mundial e a maior participação nas trocas globais proporcionem ganhos de competitividade $e$ margem para o desenvolvimento econômico, uma política industrial consistente se revela importante. Esta pode ser vista como um instrumento para ampliar a capacidade industrial garantindo condições mais competitivas no mercado interno e externo

Contudo, com o processo de integração econômica, as possibilidades de formulação de políticas industriais independentes tornam-se continuamente comprometidas. Por isso a importância da discussão sobre a regulamentação internacional da matéria, especialmente para países em desenvolvimento, pois ao mesmo tempo em que é interessante manter a flexibilidade para formulação de políticas de desenvolvimento, também é importante adequar a concessão de subsídios a disciplina internacional, uma vez que o uso indiscriminado de medidas compensatórias por outros países pode ser prejudicial. Se o mercado externo for um elemento relevante para a competitividade da indústria, ou, mesmo um dos objetivos perseguidos pela própria política industrial, a proliferação de medidas compensatórias, aplicadas por diversos países, pode vir a ameaçar a própria sobrevivência da indústria que foi incentivada.

No âmbito da OMC, estas políticas esbarram na rigidez dos Acordos sobre Medidas de Investimento Relacionadas ao Comércio (TRIMS), sobre Medidas de Direito de Propriedade Intelectual (TRIPS) e sobre Subsídios e Medidas Compensatórias (ASMC). Como escrevem Bora, Lloyd e Pangestu,

\footnotetext{
"the effect of WTO rules is not so much to exclude the role of government, but rather to shift its emphasis to the supply side. Policies that are related to infrastructure, human capital formation, innovation and diffusion of technology, capacity building and competition policies are now critical for export competitiveness. These policies need to be complemented by a stable exchange rate that does not penalize (or favour) exports. These are generic pro-development policies; that is, they are
} 
not confined to and do not favour particular industries producers" ${ }^{\prime 18}$.

Conforme discutido no artigo, os subsídios de disponibilidade geral não são acionáveis. A análise do ASMC da OMC indica que políticas industriais nas quais predominem medidas consideradas como "horizontais", de acesso irrestrito e não-seletivo, seriam mais adequadas por serem menos distorcidas em termos de alocação de recursos. Todavia, a falta de recursos nos países em desenvolvimento impede que eles desenvolvam política genéricas de subsídios, por isso a injustiça dos artigos $1^{\circ}$ e $2^{\circ}$ do ASMC ao impor o critério da especialidade para proibir os subsídios.

Dentro destes limites legais, há ainda muitas possibilidades a serem exploradas. A tarefa é identificar, com destaque para as limitações como o Brasil pode fazer uso de medidas nele previstas. Assim foram elaboradas as Diretrizes da Política Industrial, Tecnológica e de Comércio Exterior visando fazer da inserção internacional uma fonte de ganhos de competitividade e de liberdade para o desenvolvimento econômico. Vêm, assim, afastar visões ortodoxas contrárias a políticas de incentivo tecnológico em países em desenvolvimento, substituído-as por idéias que contribuam na construção do papel do Estado como promotor do desenvolvimento nacional

No atual estágio da economia brasileira, o processo de liberalização comercial pode ser melhor aproveitado através da articulação entre os mecanismos de política industrial e comercial.A capacidade de articulação de um projeto nacional com a inserção global que vai determinar o futuro das economias. Desperdiçar a oportunidade de efetivar uma política sustentável de desenvolvimento tecnológico é impedir muitas outras transformações fundamentais para o país.

\section{REFERÊNCIAS}

ABREU, Marcela de Paiva. Which "Industrial Policies" are meaningful for Latin America? Buenos Aires: IDB - INTAL, 2006.

${ }^{18}$ BORA, Bijit; LLOYD, Peter J.; PANGESTU, Mari. Industrial Policy and the WTO. Genebra: WTO Secretariat, 1999. p. 33

Revista Brasileira de Direito Internacional, Curitiba, v.7, n.7, jan./jun.2008 
ACCIOLY, Elizabeth. Mercosul \& União Européia: estrutura jurídicoinstitucional. 3.ed. Curitiba: Juruá, 2004.

BARRAL, Welber (Org.) O Brasil e a OMC. 2.ed. Curitiba: Juruá, 2002.

BORA, Bijit; LLOYD, Peter J.; PANGESTU, Mari. Industrial Policy and the WTO. Genebra: WTO Secretariat, 1999.

BRASIL. MINISTÉRIO DO DESENVOLVIMENTO, INDÚSTRIA E COMÉRCIO (2004). Diretrizes da Política Industrial, Tecnológica e de Comércio Exterior. Brasília: 2004.

BROGINI, Gilvan Damiani. OMC e Indústria Nacional: salvaguardas para o desenvolvimento. São Paulo: Aduaneiras, 2004.

CORNET, Lean Naidin; LEMME, Marta Calmon; GADELHA, Maria Fernanda. As negociações de subsídios na Rodada Doha: avaliação e implicações de política industrial. In Latin American Trade Networkin Working Paper $n^{\circ} 65$. Setembro, 2006.

CARVALHO, Maria Auxiliadora de; SILVA, César Roberto Leite de. Economia Internacional. São Paulo: Saraiva, 2000.

CHEREM, Mônica Teresa Costa Sousa; DI SENA JR., Roberto (Org.). Comércio Internacional e Desenvolvimento: uma perspectiva brasileira. São Paulo: Saraiva, 2004.

FARINA, Elizabeth Maria Mercier Querino et alli. Competitividade: Mercado, Estado e Organizações. São Paulo: Singular, 1997.

FLEURY, Afonso; FLEURY, Maria Tereza Leme (Org.). Política Industrial 1. São Paulo: Publifolha, 2004.

FLEURY, Afonso; FLEURY, Maria Tereza Leme (Org.). Política Industrial 2. São Paulo: Publifolha, 2004.

GRAU, Eros Roberto. A Ordem Econômica na Constituição de 1988 (interpretação e crítica).5.ed. São Paulo: Editora RT, 1990.

GRAU, Eros Roberto. Planejamento Econômico e Regra Jurídica. São Paulo: Editora RT, 1997.

GUIMARÃES, Samuel Pinheiro. Desafios Brasileiros na Era dos Gigantes. Rio de Janeiro: Contraponto, 2005.

INSTITUTO de Estudos para o Desenvolvimento Industrial. Política Industrial, Comércio Exterior e Política de Exportação. In: IEDI, Industria e 
Desenvolvimento. Uma análise dos Anos 90 e uma Agenda de Política de Desenvolvimento Industrial para a Nova Década. Nov 2000.

KLEIN, Vinícius. Questões Acerca de uma Política Industrial do Mercosul. In MENEZES, Wagner (Coord.) Estudos de Direito Internacional. Vol. II. Curitiba: Juruá, 2006.

MERCADANTE, Aramita de A. Mercosul: salvaguardas, dumping e subsídios. In: BAPTISTA, Luiz O.: MERCADANTE, Aramita de A.; CASELLA, Paulo B. (Org.). Mercosul: das negociações à implantação. São Paulo: LTr, 1994. p. 179-207.

NASSIF, André Luiz. A Articulação das Políticas Industrial e Comercial nas Economias em Desenvolvimento Contemporâneas: Uma Discussão Analítica. In Revista de Economia Política. Vol 20. n². Abril-Junho 2000.

SCHUMPETER, Joseph A. Teoria do Desenvolvimento Econômico. São Paulo: Abril, 1982.

SCHIFF, Maurice; WINTERS, L. Alan. Regional Integration and Development. Washington: World Bank, 2003.

SEN, Amartya. Desenvolvimento como Liberdade. São Paulo: Companhia das Letras, 2000.

SOUZA, Washington Peluso Albino de. Primeiras Linhas de Direito Econômico. 5.ed. São Paulo: LTr, 2003.

THORSTENSEN, Vera; JANK, Marcos S. O Brasil e os Grandes Temas do Comércio Internacional. São Paulo: Lex Editora; Aduaneiras, 2005.

TONI, Jackson de. A Inovação Tecnológica, políticas públicas e o Futuro da Indústria no Brasil in Opinio, n. 17, 2006 Canoas.

WTO. Canada - Export Credits and Loan Guarantees for Regional Aircraft. DS/222. 22 de Janeiro de 2002.

WTO. Canada - Measures Affecting the export of Civilian Aircrafts. DS/70. 14 de Abril de 1999.

WTO. Canada - Softwood Lumber. DS/236 e DS/257.

WTO. Export Financing Programme for Aircraft. DS/46. 14 de Abril de 1999.

WTO. Korea - Measures Affecting Trade in Commercial Vessel. DS/273. 21 de Outubro de 2002.

Revista Brasileira de Direito Internacional, Curitiba, v.7, n.7, jan./jun.2008 
WTO. United States - Subsidies on Upland Cotton. DS/267. 8 de Setembro de 2004.

WTO. Indonesia - Autos. WT/DS54/R, WT/DS55/R,WT/DS56/R, WT/DS59/R, WT/DS64/R. 